\title{
HABERMAS E A TEORIA DA LEGITIMIDADE DA JURISDIÇÃO CONSTITUCIONAL
}

\author{
WALBER AGRA*
}

\begin{abstract}
RESUMO: O artigo examina a posição de Habermas em relação à legitimidade da jurisdição constitucional pelo procedimento. Este procedimento terá coerção única exercida pelo melhor argumento, em uma relação de complementaridade entre o Direito e a moral. A idéia habermasiana é estabelecer uma jurisdição constitucional com base numa democracia participativa centrada no procedimento do processo comunicativo.

PALAVRAS-CHAVE: Jurisdição Constitucional; Legitimidade; Procedimento.
\end{abstract}

\begin{abstract}
The article examines the position of Habermas regarding the legitimacy of the constitutional jurisdiction by procedure. This procedure will have its only coercion exercised by the best argument, in a complementary relationship between the law and morals. The habermasian's idea is to establish a constitutional jurisdiction based on a participatory democracy centered in the procedure of the communicative process. KEYWORDS: Constitutional Jurisdiction; Legitimacy; Procedure.
\end{abstract}

SUMÁRIO: 1) A Questão da Legitimidade em Jürgen Habermas; 1.1) Noção de Razão Comunicativa; 2) A Concepção de Direito em Habermas; 3) Necessidade de Criação de um Espaço Público; 4) Crítica à Teoria Sistêmica; 5) A Diferença de Concepção da Legitimidade pelo Procedimento em Habermas e Weber; 6) A Legitimidade da Jurisdição Constitucional em Habermas; 7) Bibliografia.

SUMMARY: 1) The Question of Legitimacy in Jürgen Habermas, 1.1) Concept of Communicative Reason, 2) The design of law in Habermas, 3) Creating a Need for Public Space, 4) The Critical Systemic Theory; 5) The Conception Difference of Legitimacy by Procedure in Habermas and Weber; 6) The Legitimacy of the Constitutional Jurisdiction in Habermas; 7) Bibliography.

\section{A QUESTÃO DA LEGITIMIDADE EM JÜRGEN HABERMAS}

Para Habermas a jurisdição constitucional, que se baseia no ordenamento jurídico, tem como orientação princípios de natureza ética e moral, com a intenção de impedir o estabelecimento de ordenamentos jurídicos como o nazista e o fascista que praticamente aboliram os direitos fundamentais. Com esse objetivo ele propõe uma re-moralização do Direito, cujas normas jurídicas teriam como vetores parâmetros

\footnotetext{
* Mestre pela UFPE, Doutor pela UFPE/Universitá degli Studio di Firenze; Professor Universitário da SCES e da Universidade Católica de Pernambuco; Professor permanente do Mestrado da UNICAP; Professor Visitante da Università di Studio di Lecce; Membro do Conselho Científico do Doutorado da Universidade de Lecce; Professor Visitante do Mestrado e do Doutorado da UFPE; Procurador do Estado de Pernambuco.
} 
éticos que sinalizariam o contorno geral do seu conteúdo. Os argumentos morais seriam inseridos dentro do ordenamento por intermédio dos princípios jurídicos. ${ }^{1}$

\section{1) Noção de Razão Comunicativa}

A razão comunicativa pode ser situada como representante da filosofia pós-positivista, na sua tentativa de superação da filosofia analítica kelseniana, fundamentada na razão no âmbito do discurso prático. A filosofia analítica kelseniana pode ser definida como a filosofia cujo método fundamental é a análise, com o escopo de resolver qualquer raciocínio mediante silogismos, que constituem suas premissas evidentes, buscando as provas necessárias no próprio silogismo. ${ }^{2}$ Por sua vez, os silogismos são pressupostos que através de raciocínio dedutivo desencadeiam outros

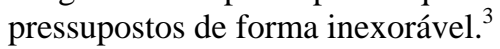

A base da filosofia jurídica de Habermas reside na comunicação humana, especificamente no conceito de razão comunicativa. Em uma sociedade multicultural onde os homens vivem hodiernamente, os processos de comunicação são de capital importância, tanto para a estabilidade social como para a solução dos litígios.

A essência desse conceito é o deslocamento da racionalidade e da legitimidade do sujeito para o procedimento da produção normativa, garantindo a previsibilidade do processo comunicativo. Enquanto, no positivismo jurídico a racionalidade está centrada no juiz, na razão comunicativa a racionalidade está centrada no processo argumentativo, por meio do debate entre os argumentos que alicerçam as estruturas normativas.

Os argumentos estabelecem racionalidade às decisões judiciais, assegurando a previsibilidade do procedimento, eliminando a surpresa da escolha de um argumento que não fora por ele previsto. A argumentação forma uma ilusória justificação para as decisões judiciais, com se fosse o seu principal esteio, esquecendo que muitas vezes são as decisões que justificam a argumentação escolhida.

A razão comunicativa difere do fundamento da razão centrada no sujeito, que é caudatária do movimento racionalista, configurando-se como a ferramenta imprescindível da modernidade. A razão centrada no sujeito permitiu a emancipação do pensamento crítico, sem as amarras da doutrina teocrática da Igreja, incentivou o humanismo, colocando o homem como centro dos acontecimentos. Ela tem como sua principal característica a auto-referência no ser cognoscente, a despeito da relação com o objeto cognoscível.

\footnotetext{
${ }^{1}$ HABERMAS, Jürgen. Fatti e Norme. Contributi a uma Teoria Discorsiva Del Diritto e Della Democrazia. Trad. Leonardo Ceppa. Milano: Edizione Guerini e Associati, 1996. p. 313

${ }^{2}$ Nicola Abbagnano assim define Filosofia Analítica: "Em geral, uma disciplina ou uma parte de disciplina cujo método fundamental é a análise. Aristóteles chamou de análise a parte da lógica que visa resolver qualquer raciocínio na figuras fundamentais dos silogismos (Primeiros analíticos) e qualquer prova nos próprios silogismos e nos primeiros princípios, que constituem suas premissas evidentes (Segundos analíticos)”. ABBAGNANO, Nicola. Dicionário de Filosofia. Tradução: Alfredo Bosi. São Paulo: Martins Fontes, 2000. p. 54

${ }^{3}$ Nicola Abbagnano também define silogismo: "Essa palavra que na origem significava cálculo e era empregada por Platão para o raciocínio em geral, foi adotada por Aristóteles para indicar o tipo perfeito do raciocínio dedutivo, definido como um discurso em que, postas algumas coisas, outras se seguem necessariamente”. ABBAGNANO, Nicola. Dicionário de Filosofia. Tradução: Alfredo Bosi. São Paulo: Martins Fontes, 2000. p. 896.
} 
A razão comunicativa não tem o propósito de sepultar os avanços do movimento racionalista, muito pelo contrário, ela visa permitir um avanço nos seus postulados, mantendo o mesmo potencial crítico. Ambos são movimentos racionalistas, o primeiro, com a razão desenvolvida a partir do procedimento do processo comunicativo e o segundo, com a razão centrada no sujeito.

A teoria de Habermas parte de um processo comunicativo, em uma relação interpessoal, na qual se estabelecem avaliações do próprio sujeito e do alter no processo comunicativo. A sua característica preponderante é a substância procedimental, em que a previsibilidade e racionalidade da comunicação são garantidas por certas regras, anteriormente estabelecidas. Esses princípios que orientarão o processo comunicativo devem ser princípios gerais de racionalidade e valores éticos, a partir dos quais estes orientam a estrutura dos argumentos empregados.

O discurso utilizado no processo de comunicação não pode ser aleatório, mas um discurso racional, pautado por parâmetros pré-fixados. Explica Habermas: "E “discurso racional” é toda a tentativa de entendimento sobre pretensões de validade problemáticas, na medida em que ele se realiza sob condições da comunicação que permitem o movimento livre de temas e contribuições, informações e argumentos no interior de um espaço público constituído através de obrigações ilocucionárias. Indiretamente a expressão refere-se também a negociações, na medida em que estas são reguladas através de procedimentos fundamentados discursivamente". 4

A validade das decisões judiciais tem que estar calcada na fundamentação do argumento que consiga o maior assentimento da sociedade civil. Todavia, para que esse argumento possa auferir uma densa legitimidade é necessário que ele possa ser discutido por amplos setores da sociedade, possibilitando a crítica para a sua melhoria.

\section{A CONCEPÇÃO DE DIREITO EM HABERMAS}

Habermas busca a superação da concepção de Direito clássico, que tem como característica a legalidade, a positividade e o formalismo. Legalista na medida em que o padrão normativo determinante é a lei, por sua vez representante da soberania popular. Positividade no sentido de que as normas devem ser escritas para possibilitarem um maior grau de segurança jurídica. E formalismo que se fortalece com a sistematização do ordenamento jurídico, em que a criação e aplicação das leis estão vinculadas a procedimentos de conteúdo eminentemente formal.

Para Max Weber, que foi um dos formuladores da concepção clássica do Direito, as características fundamentais do ordenamento jurídico ocidental moderno de administração da justiça são: a criação normativa de forma racional e a natureza sistêmica do Direito, o que garante ao fenômeno jurídico um crescente particularismo. ${ }^{5}$

O Direito clássico nasce com o Estado secular, sepultando o Estado Absolutista, onde as leis teocráticas, baseadas na vontade divina, cedem lugar às leis baseadas na

\footnotetext{
${ }^{4}$ HABERMAS, Jürgen. Direito e Democracia. Entre Facticidade e Validade. V. I. Trad. Flávio Beno Siebeneichler, Rio de Janeiro: Tempo Brasileiro, 1997. p. 142.

${ }^{5}$ WEBER, Max. Economia e Società. Sociologia Del Diritto. III. Trad: Giorgio Giordano. Milano: Edizione di Comunita, 1995. p. 186.
} 
vontade humana. ${ }^{6}$ A normatividade de suas leis é amparada na possibilidade de implementação de uma sanção, defluindo como uma de suas características principais a objetividade, atingindo a todos os cidadãos que estejam na mesma situação jurídica.

A superação dessa concepção de Direito clássico baseia-se no estabelecimento de procedimentos racionais que norteiam o medium comunicativo para a obtenção do consenso, que será efetuado com a participação efetiva da sociedade. A função dos parâmetros jurídico-morais é indicar um consenso todas as vezes que ele não puder ser realizado pelo âmbito comunicativo.

O Direito moderno, para Habermas, se caracteriza pelas exigências concomitantes de positivação e de fundamentação argumentativas, baseadas em parâmetros éticos morais. No que se difere dos positivistas tradicionais que sustentam poder ser a legitimidade obtida apenas pelo procedimento, destituída de qualquer tipo de conteúdo material.

A institucionalização das decisões judiciais é realizada de uma dupla forma: obedecendo ao procedimento que fora previamente estipulado, quando cada ato acarretará uma conseqüência prevista no ordenamento, e que a decisão proferida seja sustentada pelo critério fornecido pelo melhor argumento, com a abertura de um canal para os preceitos morais.

A legitimação do Direito é obtida por meio de procedimentos, que se desenrolam através de uma seqüência de atos jurídicos, cuja decisão será tomada com base no argumento mais robusto, imbuída de preceitos morais. Assim, dessa forma, a legitimação procedimental do Direito fundamenta-se em princípios morais. A única coerção admitida durante o procedimento judicial é a força exercida pelo melhor argumento, em uma relação de complementaridade entre o Direito e a moral.

Nesse processo há uma interseção de três fatores que atuam simultaneamente: o jurídico, o político e o moral. O jurídico que influencia o procedimento do processo de decisão; o político que estrutura o espaço público e o moral que oferece um alicerce de fundamentação para as estruturas normativas.

A influência de vetores ético-morais na seara do Direito é também defendida por Dworkin. ${ }^{7}$ Segundo o qual o direito e a moral são os alicerces para as decisões da jurisdição constitucional. Ele assevera que os princípios morais são elementos intrínsecos às normas jurídicas, mesmo que não tenham sido por eles acolhidas, devendo ser concebidas de modo implícito, configurando-se como condição imprescindível para as decisões judiciais. (citar Dworkin).

O espaço público é o elo de ligação entre a política e o Direito, onde os cidadãos respaldariam o melhor argumento para que este pudesse alicerçar a decisão. A ligação entre os princípios morais e a política origina-se no fato de que esta recebe daquela

\footnotetext{
${ }^{6}$ Doutrina o culto professor Nelson Saldanha: “ O processo de secularização corresponde a uma gradual transformação ocorrida em determinadas sociedades, transitando de um padrão predominantemente religioso para formas preferentemente "leigas" (ou racionais) de vida. Tal processo ocorreu exemplarmente na Grécia do Século V A. C. e no ocidente do Século XVIII, com antecipações que radicam no Humanismo renascentista”. SALDANHA, Nelson. Da Teologia à Metodologia. Secularização e Crise no Pensamento Jurídico. Belo Horizonte: Del Rey, 1993. p. 57.

${ }^{7}$ DWORKIN, Ronald. Uma Questão de Princípio. Trad. Luís Carlos Borges. São Paulo: Martins Fontes, 2000. p. 7.
} 
os argumentos que permitiriam estabelecer determinados consensos na sociedade. Segundo Stanley Kleinberg, os argumentos morais são uma importante saída para se tentar resolver controvérsias políticas de forma racional. ${ }^{8}$

Na concepção moderna de Direito de Habermas assume relevante significado o conceito de direito subjetivo. Eles são espaços privativos de atuação dos cidadãos, onde eles podem exercer livremente sua vontade, sendo constituídos para garantir igual liberdade à comunidade de sujeitos de direito. Na circunscrição desse espaço não cabe atuação dos entes estatais no sentido de cercear os direitos subjetivos, mas apenas no sentido de limitar a sua atuação.

Os direitos subjetivos, para serem concretizados de forma plena, necessitam ser definidos através de uma idéia de reciprocidade, na qual cada cidadão é co-responsável pelo exercício do direito de outrem, de forma que exista uma responsabilidade difusa por todo o ordenamento jurídico. Apenas em uma sociedade livre, onde os cidadãos possam discutir os seus interesses no espaço público, por meio de argumentos racionais, é que os direitos subjetivos podem ser realizados, devido à co-responsabilidade que existirá dentro das relações.

Diante da liberdade de ação que permeia os direitos subjetivos, dentro do espaço de atuação previamente estipulado pelas disposições normativas, os cidadãos se comportam como responsáveis pela elaboração do ordenamento jurídico, em uma co-autoria concretizada pela livre atuação na elaboração argumentativa no espaço público. Portanto, para Habermas, os direitos subjetivos são responsáveis pela reciprocidade de direitos e deveres dos cidadãos e pela co-autoria do ordenamento jurídico.

Outra concepção, que assume especial relevo para a teoria habermasiana, diz respeito ao caráter instrumental do Direito, decorrente dos direitos subjetivos dos cidadãos, em que há uma atuação pautada no interesse singular. O particularismo na ação de cada cidadão é arrimado na seara do espaço subjetivo ofertado, permitindo um amplo espaço para a estruturação da teoria discursiva do Direito.

A teoria habermasiana somente pode ser construída em um Estado Democrático Social de Direito. Democrático, no sentido de que as decisões devem ser tomadas de forma coletiva, assegurando uma ampla participação popular; Direito, porque o parâmetro legal deve ser o alicerce da sociedade, pairando acima das vontades individuais e de grupos econômicos; Social para atender as necessidades dos hipossuficientes existentes na sociedade.

Outra condição para o florescimento da teoria discursiva é a existência de uma cultura em que os cidadãos se sintam obrigados a participar das decisões políticas, sendo responsáveis individualmente pela gerência da coisa pública. Estas duas condições devem ser pautadas em fundamentos éticos que ajudem a previsibilidade dos fundamentos racionais, orientadores da teoria discursiva.

Elemento imprescindível para a teoria discursiva são os direitos fundamentais, funcionando como pressupostos para o debate no espaço público. Não são concebidos

${ }^{8}$ KLEINBERG, Stanley S. The Necessity and Limitations of Rational Argument. Massachusetts: Blackwell, 1991. p. 35. 
apenas do ponto de vista liberal burguês, mas entendidos como condições, procedimentos, para o processo democrático de escolha das decisões judiciais. Princípios como a liberdade de consciência, liberdade de expressão, vedação à censura e à licença, entre outros, são pressupostos substancias para a participação dos cidadãos no espaço público. A teoria do espaço público também é defendida por outros autores, como Cass Sunstein. ${ }^{9}$

Os direitos fundamentais, dentro da ótica do agir comunicativo, passam a ser vistos como requisitos procedimentais para a interação comunicativa, sem a contingência de apresentar uma validade metafísica, consonante com a lição de Norberto Bobbio de que não há mais necessidade de se buscar fundamentação metafísica para os direitos fundamentais. $^{10}$

Os direitos fundamentais também funcionam como limites ao regime democrático, que não podem ser tolhidos, mesmo que legitimados pela vontade popular. Desempenham, dessa forma, uma dupla função, sendo ao mesmo temo requisito e limite para a democracia.

Habermas não pode ser entendido como um adepto da escola liberal clássica, para ele os direitos fundamentais, relacionados à autonomia privada, devem ser entendidos como supedâneos da autonomia política dos cidadãos, com o escopo de aprimoramento do regime democrático. Os direitos políticos dos cidadãos somente podem ser desenvolvidos se forem amparados nos direitos fundamentais da autonomia privada, que asseguram a liberdade imprescindível para a participação no processo democrático, acrescido de determinadas condições materiais que devem ser ofertadas a todos os cidadãos, inclusive configurando-se como requisito efetivo da autonomia política dos cidadãos.

\section{NECESSIDADE DE CRIAÇÃO DE UM ESPAÇO PÚBLICO}

Com o efeito do desenvolvimento da razão comunicativa, o conceito de democracia passa a ser estruturado juntamente com o conceito de espaço público, partindo do pressuposto de que em sociedades altamente complexas como são as sociedades pós-modernas, há a necessidade de se estabelecer um locus onde as discussões devem ser travadas.

Em contraposição à democracia liberal, Habermas elabora a democracia discursiva, em que para as decisões serem tomadas, não necessita de uma assembléia de cidadãos, mas é imprescindível que todos tenham acesso ao espaço público e possam participar do debate acerca das decisões. A democracia deixa de ser visualizada exclusivamente como democracia representativa, necessitando que as pretensões normativas passem por intensos debates públicos.

\footnotetext{
${ }^{9}$ SUNSTEIN, Cass. R. Republic. Com. New Jersey: Princeton University, 2002. p. 27.

10 "Mas, quando digo que o problema mais urgente que temos de enfrentar não é o problema do fundamento, mas o das garantias, quero dizer que consideramos o problema do fundamento não como inexistente, mas como - em certo sentido - resolvido, ou seja, como um problema cuja solução já não devemos nos preocupar. Com efeito, pode-se dizer que o problema do fundamento dos direitos humanos teve sua solução atual na Declaração Universal dos Direitos do Homem, aprovada pela Assembléia-Geral das Nações Unidas, em 10 de dezembro de 1948”. BOBBIO, Norberto. A Era dos Direitos. 16ª Tiragem. Trad. Carlos Nelson Coutinho. Rio de Janeiro: Editora Campus, 1992. p. 26.
} 
Para isso é necessária a construção de um espaço público, onde as decisões judiciais possam ser esclarecidas e discutidas. A importância da razão comunicativa de Habermas é regulamentar os mecanismos que possibilitem o funcionamento adequado desse espaço público, universalizando a participação de todos.

A razão comunicativa atua no sentido de fortalecer o espaço público, onde as atividades dos entes estatais são legitimadas por intermédio de argumentos e contraargumentos. Através da abertura desse espaço de discussão, cada atividade estatal tem que ser legitimada por argumentos racionais.

O telos do espaço público é institucionalizar a legitimação do direito, a partir da construção de um acordo, ou consenso, que ampare as proposituras normativas. Pelo caráter pós-moderno da razão comunicativa, o acordo estará amparado no argumento que obtiver o maior consenso no espaço público, devendo obrigatoriamente estar imbuído de fundamentos ético-racionais, que obedeçam ao procedimento previamente determinado. Para se saber se o acordo obtido é racional ou não, deve-se verificar o procedimento adotado, pois é esse o que vai validar a estrutura normativa.

A função das estruturas normativas e dos parâmetros ético-racionais é garantir a realização do consenso, todas as vezes que ele não puder ser realizado pelo processo comunicativo.

O espaço público deve ser o grande legitimador das decisões judiciais. Assim, quanto maior for a simetria entre o espaço público e o Poder Judiciário, maior será o consenso extraído de suas decisões. Ele dever ser a ligação entre a vontade produzida pelos atores sociais e as instâncias estruturadoras das decisões judiciais.

O ordenamento jurídico tem a função de, além de normatizar as expectativas procedimentais do espaço público, regulamentar, de forma mais democrática possível, o acesso da população aos debates acerca das decisões judiciais. A discussão deve possibilitar a interação entre o espaço público e os órgãos estatais. A definição de como os debates são realizados é feita por procedimentos que serão previamente definidos.

O espaço público deve possibilitar aos cidadãos iguais chances de influenciar na tomada das decisões. E essa participação democrática inclusive é um limite às próprias decisões da maioria, que terão que respeitar a participação de todos no processo de tomada de escolha, ou seja, o limite para as deliberações é a manutenção do procedimento democrático.

A implementação da racionalidade nos procedimentos jurídicos tende a criar um espaço para uma democracia procedimental, onde as discussões acerca do melhor argumento a ser empregado ocorre no espaço público, com a possibilidade de participação de todos os interessados. É estabelecido que o pressuposto para a utilização do argumento usado na decisão seja aquele que obtiver maior densidade de aceitação. Portanto, os argumentos empregados nos debates públicos devem se revestir da maior razoabilidade possível, para que obtenham consenso no espaço público.

Os debates realizados no espaço público devem ser proferidos em linguagem clara para possibilitar o seu conhecimento pela maior parte possível da população. A utilização de linguagem técnica deve ser a mais imprescindível possível, com a finalidade de se evitar o formalismo que tanto assola a cultura jurídica. Do choque de 
argumento e contra-argumentos havido no debate é que advém a legitimidade das decisões judiciais.

A maior eficácia do ordenamento jurídico será obtida quando a população deixar sua posição de expectador passivo e inerte, para tornar-se sujeito de direito, agente ativo na construção da decisão judicial. Quanto maior for a participação da sociedade no debate dos principais temas postos à apreciação judicial, maior será a eficácia concretiva do ordenamento jurídico.

O espaço público proporciona que o ordenamento jurídico possa ser emanado da vontade discursiva de seus cidadãos, fazendo com que ele possa apresentar um maior teor de legitimidade, haja vista ter sido construído mediante um processo de normogénese, previamente estabelecido, calcado nos direitos fundamentais e na soberania popular. A legitimidade para Habermas advém de um processo comunicativo que é concretizado no espaço público.

Se o processo legislativo não estiver calcado nos direitos fundamentais e na soberania popular, dois limites na elaboração do ordenamento jurídico, a legitimidade do ordenamento estará obnubilada. A legalidade, proporcionada pelo processo legislativo, é reflexo da opinião discursiva dos membros da comunidade, somada à vontade dos membros da coletividade.

Como pressuposto do espaço público, podemos mencionar o princípio da igualdade comunicativa, em que cada cidadão tenha a mesma oportunidade de participar do processo discursivo, possibilitando que o argumento que obtenha o maior grau de consenso possa ser utilizado.

A fragilização do espaço público, pode ocorrer de vários modos. Um deles é a tecnização do discurso, com o rebuscamento da linguagem, através do uso de vários termos técnicos, que impedem à maioria da população compreender a discussão em setores imperiosos da vida nacional, como por exemplo, as discussões sobre economia. Emprega-se um tecnicismo exagerado para colocar fora do debate público as questões essenciais, com o argumento de que seriam assuntos eminentemente técnicos.

O fator teleológico para a construção da teoria do espaço público foi servir com instrumento de legitimação para as decisões judiciais, principalmente àquelas inerentes à jurisdição constitucional, em que o Poder Judiciário tem que intervir em vários seguimentos da sociedade para garantir direitos às prerrogativas constitucionais.

\section{CRÍTICA À TEORIA SISTÊMICA}

A crítica feita por Habermas à teoria sistêmica reside no fato de que ela gera uma autonomização do ordenamento jurídico, que produz um alheamento das reais condições existentes na sociedade.

A finalidade da razão comunicativa é buscar o entendimento, mediante parâmetros que orientem a comunicação, contrapondo-se à teoria dos sistemas que busca o alcance de determinados fins, por intermédio de um código comunicativo próprio, altamente técnico, que poucos são aqueles que podem compreendê-lo. A crítica habermasiana à teoria sistêmica reside no fato de que ela reduz a complexidade da seara fática, produzindo uma desconexão com a realidade. 
Os subsistemas sociais mantêm uma constante interação com o meio ambiente e com outros subsistemas, por meio de constantes processos de intercâmbio. Ocorre que para preservar a integridade sistêmica, as informações que adentram no subsistema têm que ser transformadas em categorias abstratas para que sejam inteligíveis pelas suas estruturas. Destarte, há uma redução da complexidade das informações coletadas, já que elas, obrigatoriamente, têm que se adequar à linguagem vigorante no sistema, fazendo parte de um dos seus elementos. ${ }^{11}$

Segundo Habermas, a teoria sistêmica produz uma "colonização do mundo da vida”, pois as informações que adentram no subsistema jurídico são destituídas de conteúdo, contribuindo de forma direta para alienar os cidadãos. As conseqüências ocasionadas são drásticas para a democracia, haja vista que a legitimação provém da auto-programação do poder, realizada pelo aparelho burocrático, partindo de uma concepção de completude do sistema, autopoesis.

A teoria dos sistemas de Luhmann parte do pressuposto de que as estruturas internas reduzem a diferença entre o sistema e o meio ambiente, operando uma seletividade nas informações provenientes do exterior. Essas estruturas são essenciais para a auto-referência do sistema, mesmo que comprometa os canais de ligação com a sociedade. Para a teoria luhmanniana, a complexidade apenas provoca uma evolução sócio-cultural quando provoca uma modificação na estrutura da sociedade, no que compromete a auto-referência. ${ }^{12}$

A programação do universo jurídico passa a ser feita por elementos diferentes dos elementos que moldam o mundo da vida, o que acarreta um gap, com a perda de eficácia concretiva das normas jurídicas. Como a estrutura do ordenamento jurídico e o mundo da vida são diferentes, o cidadão comum não pode entender o funcionamento da seara normativa, o que acarreta uma perda de legitimidade na sua aplicação, provocando um distanciamento da população, conseqüência da sua alienação.

Como conseqüência desse pensamento, em que há uma autonomia do fenômeno jurídico, em dissonância com a legitimação popular ou com qualquer tipo de legitimidade haurida da sociedade, estruturam-se determinados órgãos que passam a exercer o poder sem qualquer tipo de controle por parte da sociedade. O substrato de sua legitimação é baseado em um escalonamento normativo, ausente interpenetrações por parte da seara fática. Como por exemplo, as agências reguladoras ou a previsão de autonomia para o Banco Central cujos diretores têm uma considerável gama de poder, sem contar com a aquiescência da população.

11 “Como todo sistema, o procedimento reduz a complexidade do mundo circundante selecionando determinadas alternativas de conduta em detrimento de outras que não são interiorizadas e que não podem ser arguïdas, não importando em que medida tenham a ver com a realidade dos fatos. De nada adianta argumentar que determinada prova dos autos foi forjada se não se puder faze-lo através das regras préfixadas na estrutura do próprio procedimento, tais como a apresentação de provas em contrário, dentro da forma prescrita em tempo hábil etc. Se isso não for possível, a parte prejudicada vê-se constrangida a aceitar a decisão como legítima, embora permaneça convencida de que foi ludibriada”. ADEODATO, João Maurício. Ética e Retórica. Para uma Teoria da Dogmática Jurídica. São Paulo: Saraiva, 2003. p. 64.

12 BARALDI, Cláudio; CORSI, Giancarlo; ESPOSITO, Elena. Semântica e Comunicazione. L'evoluzione delle idee nella prospettiva sociológica di Niklas Luhmann. Bologna: Clueb, 1987. p. 41. 
Reproduzindo-se de forma interna, a teoria sistêmica não necessita de legitimidade para justificar as suas decisões, não havendo necessidade de argumentá-las. Esclarece Cláudio Pereira de Souza Neto: "Presente nos ideais cientificistas que caracterizam, em parte, o pensamento iluminista, a razão centrada no sujeito levou a tecnificação e a autonomização sistêmica das esferas do estado e do mercado. Com tal processo de autonomização, esses subsistemas passaram a exercer uma coordenação automática da vida do homem concreto, que está no mundo vivido, dispensando-se da necessidade de justificar discursivamente suas ações". ${ }^{13}$

Para Habermas a linguagem do subsistema jurídico tem que estar respaldada no mundo da vida, onde as instituições basilares da sociedade são racionalizadas por meio de "um médio de linguagem”, que é a forma de obtenção de um consenso mais estável. Todavia, o processo de intercâmbio entre o subsistema jurídico e o meio ambiente precisa ser estabelecido, mediante padrões de racionalidade, assegurando a interação comunicativa.

A teoria habermasiana divide em duas ordens as instituições sociais: de primeira e de segunda ordem. De primeira ordem são aquelas que pertencem à seara fática, à seqüência natural do desenrolar dos fatos naturais. De segunda ordem são aquelas que não fazem parte intrinsecamente da ordem da vida, pois as relações sociais de primeira ordem lhe são independentes.

O Direito é considerado como uma instituição de segunda ordem porque é externo à seara fática, desenvolvendo-se não por uma seqüência natural de fatos, mas por meio de disposições normativas implementadas pelo homem. Assevera Luiz Moreira: "Mas por que o Direito é uma instituição de segunda ordem? Porque as diversas vivências sociais originárias brotam de um eticidade tradicional, de um universo de compreensão que, como tal, é compartilhado, de um horizonte de sentido comum, e não a partir dos termos de uma manifestação social juridicizante. Pois, nesse sentido, o Direito é uma instituição artificial que ocupa uma posição externa em relação à vida e ao modo como esta se reproduz em termos societários”. ${ }^{14}$

A principal crítica à teoria sistêmica, que prega o isolacionismo do ordenamento jurídico, é que ela tende a automatizar o direito, tornando-o um sistema que se autoreproduz sem a necessidade de elementos da seara fática. Um sistema jurídico, que se fecha às influências da sociedade, perde suas referências com a realidade, tendendo a perder sua eficácia, pois, de forma inelutável, a normalidade prevalece em detrimento de uma normatividade distorcida.

Da mesma forma, a auto-reprodução do ordenamento, isolado dos elementos externos, não contribui para arrefecer o problema da ausência de legitimidade das normas jurídicas, antes o agrava, já que passa a ser uma questão sociológica insignificante para o sistema. E ainda é um incentivo para o incremento de uma administração burocratizante, que passa a dispor de uma teoria para a sua auto-reprodução, sem a necessidade de

13 SOUZA NETO, Cláudio Pereira. Jurisdição Constitucional, Democracia e Racionalidade Prática. Rio de Janeiro: Renovar, 2002. p. 291.

${ }^{14}$ MOREIRA, Luiz. Fundamentação do Direito em Habermas. 2. ed. Belo Horizonte: Mandamentos, 2002. p. 50 . 
legitimação dos seus procedimentos. O grande objetivo da teoria sistêmica, que seria a redução da complexidade do meio ambiente que circunda o Direito, provoca uma conseqüência extremamente danosa: o deslocamento do eixo de legitimidade da soberania popular para uma legitimidade procedimental, calcada apenas em elementos intra-sistêmicos.

O processo de automatização das decisões judiciais da jurisdição constitucional, amparado apenas nos procedimentos descritos no sistema, leva à falência o espaço público que deveria legitimá-las, impedindo o fortalecimento da democracia e a participação dos cidadãos no processo de decisão.

\section{A DIFERENÇA DE CONCEPÇÃO DA LEGITIMIDADE PELO PROCEDIMENTO EM HABERMAS E WEBER}

O referencial na concepção de legitimidade entre Habermas e Weber é que ambos defendem a possibilidade de sua fundamentação residir no procedimento. A principal diferença entre eles consiste em se saber se a racionalidade auferida pelo procedimento legítimo do ordenamento jurídico, configura-se autônomo ou não, em relação à moral.

Para Weber, a racionalidade auferida pelo procedimento, que legitima o ordenamento jurídico, é autônoma em relação à moral, ilação que deflui ser a legalidade legitimada a partir de si mesma. A condição de validação do universo jurídico, para Weber, reside apenas em seu aspecto formal, sem nenhum parâmetro material, desde que fossem sejam seguidos os requisitos processuais, delineados pelo processo de normogénese.

Segundo Habermas, Weber legitima o ordenamento jurídico através do poder político, exercido segundo as regras do Estado de Direito, regido per leges e sub leges, corroborando um conceito positivista do Direito, segundo o qual os mandamentos legais são impostos pelo legislador, de acordo com um procedimento legal previamente estabelecido. $^{15}$

A racionalização formal para Weber ocorre de três modos. O primeiro por intermédio do escalonamento normativo kelseniano, cuja norma inferior é validada pela norma superior, ocupando a Constituição a posição estruturante de todo o ordenamento jurídico, que garante o seu caráter sistêmico. O segundo, se dá devido à característica das leis que são genéricas e abstratas, garantindo uniformidade jurídica para a solução dos casos apresentados, sem serem formuladas para casos específicos ou especiais. E terceiro, é que a atuação dos órgãos administrativos e judiciais ocorre de forma vinculada ao que fora determinado por prescrições normativas, de acordo com o princípio da legalidade, com a finalidade de assegurar uma aplicação metódica e calculável que se concretiza mediante leis. ${ }^{16}$

Ele considera que a influência da moral nas cominações normativas pode acarretar a debilidade da racionalidade jurídica, contribuindo para a fragilização de sua legitimidade e destruição da sua racionalidade formal. A moral, segundo a concepção

${ }^{15}$ HABERMAS, Jurgen. Direito e Moral. Trad. Sandra Lippert. Lisboa: Instituto Piaget, 1992. p. 14.

${ }^{16}$ HABERMAS, Jurgen. Direito e Moral. Trad. Sandra Lippert. Lisboa: Instituto Piaget, 1992. pp. 18-19. 
weberiana, é formada por valores subjetivos, que variam segundo os diversos interesses sociais, advindo daí sua irracionalidade. O Direito racionalmente sistematizado seria neutro em relação à moral. À medida que a moral influencia as cominações normativas, cristalizando a "des-diferenciação" entre o direito e a moral, estabelece-se a destruição paulatina da racionalidade jurídica.

Para Weber, o Direito é formalmente irracional quando no processo legislativo e na jurisdição são empregados tanto elementos que não podem ser controlados de forma racional e materialmente irracional, como quando as decisões têm por base valorações concretas do caso particular, seja de natureza ética, afetiva ou política. De forma contrária, o Direito é formalmente racional quando, sob o plano jurídico e processual, considera exclusivamente as características gerais unívocas dos casos concretos. Para conceituar o Direito materialmente racional, ele parte dos principais pressupostos: a) que cada decisão jurídica concreta é a aplicação de um princípio abstrato a um caso concreto; b) que para cada caso concreto deva ser possível, através da lógica jurídica, utilizar um dos princípios abstratos em vigor; c) que o direito objetivo possa formar um sistema dos princípios jurídicos. ${ }^{17}$

Explica Habermas o posicionamento de Weber: “Segundo Weber, o direito dispõe de uma racionalidade própria, independente da moral. A seus olhos a des-diferenciação entre o direito e moral significa, até mesmo, colocar em perigo a racionalidade do direito e, com isto, o fundamento de legitimidade do poder político legal. Weber diagnosticava uma tal moralização fatal do direito, em desenvolvimentos contemporâneos, que ele descreve como sendo uma materialização do direito formal burguês”. ${ }^{18}$

A crítica que Habermas endereça a Weber é que este omite as qualidades ético-morais do procedimento, reduzindo-o à sua esfera cognitivo-instrumental. Para o primeiro, as normas não podem ser neutras de conteúdo valorativo, seguindo a lógica finalística, mas devem ser imbuídas de vetores ético-racionais. ${ }^{19}$ Para Weber, a racionalidade jurídica não está calcada em bases ético-racionais, mas baseada conforme os fins almejados, reduzindo a racionalidade a sua função estratégica. Habermas defende que a racionalização não deveria ser segundo fins, mas sim, segundo valores.

\footnotetext{
${ }^{17}$ WEBER, Max. Economia e Società. Sociologia Del Diritto. III. Trad: Giorgio Giordano. Milano: Edizione di Comunita, 1995. pp. 16-17.

${ }^{18}$ HABERMAS, Jurgen. Direito e Moral. Trad. Sandra Lippert. Lisboa: Instituto Piaget, 1992. p. 14.

19 Esclarece Luiz Moreira, diferenciando os conceitos de legitimidade pelo procedimento de Habermas e Luhmann: “ A interpretação dada por Weber às qualidades formais do Direito propicia o esquecimento de suas qualidades prático-morais, trazidas ao Direito pela exigência de uma legitimação racional introduzida pelo princípio da fundamentação, reduzindo o Direito à sua dimensão cognitivo-instrumental. Para Habermas, Weber considera a trajetória moderna do Direito como uma configuração neutra das esferas de ação, descritas através da lógica meio-fim, caracterizada em última instância por uma ação estratégica. Diferentemente da esfera da ética e da esfera racional da vida, segundo Habermas, Weber interpreta o Direito como uma instância que tornou secundário o aspecto prático-moral e se especializou em ações do tipo instrumental estratégico. E Weber baseia sua interpretação a partir de dois indicadores empíricos, a saber: a progressiva sistematização do ordenamento jurídico através de uma lógica interna própria, pelos seu respectivo manejo por operadores tecnicamente qualificados, e a identificação da legitimidade à legalidade propiciando a transferência dos problemas de fundamentação para os de procedimento”. MOREIRA, Luiz. Fundamentação do Direito em Habermas. 2. ed. Belo Horizonte: Mandamentos, 2002. p. 44.
} 
Habermas defende que a imperiosidade de se vincular preceitos morais às disposições normativas se deveu ao vazio ontológico, verificado após a Segunda Guerra Mundial, cujos horrores cometidos chocaram a todos, independente de sua coloração partidária, mostrando como os avanços da racionalidade podem ser relegados ao ocaso. A principal causa para esse acontecimento residiu na formação de um conceito de racionalidade apenas formal e não material, destituído de qualquer tipo de conteúdo que pudesse guiar a estrutura comportamental.

A incorporação de preceitos morais ao ordenamento jurídico se dá por meio de princípios, servindo estes como a base do ordenamento. Devido à alta densidade dos princípios, estes têm a missão de realizar a ligação entre o universo metajurídico e o universo jurídico, injetando no sistema vetores axiológicos que balizarão as condutas sociais. Fazem parte do universo metajurídico em virtude do seu conteúdo moral, mas ao mesmo tempo fazem parte do universo jurídico em decorrência de sua positivação.

\section{A LEGITIMIDADE DA JURISDIÇÃO CONSTITUCIONAL EM}

\section{HABERMAS}

A principal crítica que é imputada à legitimidade da jurisdição constitucional diz respeito ao fato de que ela sempre ultrapassa os limites estipulados na separação dos poderes, estabelecendo um conflito entre o Poder Legislativo, que teoricamente tem a incumbência de realizar a produção normativa, e o Poder Judiciário, que tem a função de aplicar a lei em relação ao caso concreto. Atuando esses dois poderes em função concorrente quando o Judiciário acolmata o ordenamento jurídico diante de uma omissão do Legislativo ou assegura a concretização de uma norma programática.

As assertivas mais virulentas contra a extensão da atuação do Poder Judiciário na jurisdição constitucional consistem no medo da criação de um "governo de juízes", destituído de legitimidade popular. Entretanto, dos três poderes, o Judiciário é o mais frágil deles, porque não dispõe de nenhum meio coercitivo para garantir a eficácia de suas decisões, além de auferir a sua legitimidade de forma diferente dos outros dois.

Para Habermas, o objetivo principal da jurisdição constitucional é proteger os direitos fundamentais através decisões que obriguem os demais poderes, principalmente o Executivo, de forma vinculante, e que garanta a existência de disposição normativa quando a sua ausência for motivo impediente para o exercício de um direito.

A idéia de Habermas é estabelecer uma jurisdição constitucional com base em uma democracia participativa, que propicie a atuação efetiva dos cidadãos, o que seria um antídoto contra a ameaça de que os Tribunais Constitucionais se fechem em um ciclo autônomo de decisões. A jurisdição constitucional deve se basear em argumentos racionais, permitindo sempre a inclusão de participantes no debate público, com ligações intrínsecas com a sociedade.

Ele constrói uma teoria discursiva do Direito, fundada no agir comunicativo, que busca formar uma teoria de legitimidade cujas decisões judiciais sofram injunções diretas do espaço público que, por sua vez, deve garantir a mais completa participação isonômica dos cidadãos e da sociedade civil organizada, formando um canal entre a sociedade civil e os entes estatais. Assim define a sua teoria o próprio autor: “A teoria discursiva do Direito concebe o Estado Democrático Social de Direito 
como uma instituição de procedimento e de pressupostos comunicativos - socorrendo-se sobre o binário do direito legítimo e garantindo a autonomia privada - tornando possível uma formação discursiva da opinião e da vontade. Por sua vez, esta última, transmite o exercício da autonomia política e torna possível a legitimação da estrutura jurídica”. ${ }^{20}$

A sua teoria configura-se como procedimental porque assegura que os pressupostos racionais dos procedimentos judiciais possam direcionar a decisão tomada pelo magistrado. Esses pressupostos são construídos pelas normas jurídicas e por princípios morais, no ensejo de propiciar a maior participação possível dos cidadãos no espaço público. A sua concepção procedimental não significa que a forma deva preponderar em detrimento do conteúdo, mas sinaliza que os procedimentos jurídicos são a garantia para a realização dos pressupostos necessários para o funcionamento do espaço público.

A teoria comunicativa habermasiana se serve da política, tomada como um dos sistemas de ação existente, para tentar reduzir a complexidade da integração social, através da interação proporcionada pelo espaço público, com base em argumentos racionais. O agir comunicativo servindo-se da autonomia das vontades e do regime democrático constitui-se na força propulsora do espaço público.

Os princípios ético-morais, mesmo com o inconveniente de provocar uma incerteza quanto à sua definição, são considerados essenciais para a legitimação das decisões judiciais porque representam uma tentativa de garantir conteúdo ao regime democrático, uma esperança de equalizar o fático e o normativo dentro de uma perspectiva de consolidação dos direitos fundamentais. Eles garantem a densidade ontológica do procedimento judicial, sem que estes possam servir de obstáculo para o desenvolvimento do espaço público.

Contudo, os parâmetros que delineiam o procedimento judicial das decisões não podem ser cambiantes, pois devem ser constantes para solidificar a segurança jurídica, tão importante ao ordenamento. As diretrizes do procedimento devem ser estipuladas pelas normas jurídicas e pelos vetores ético-morais imperantes na sociedade.

As Cortes Constitucionais não devem substituir o Poder Legislativo, mas os dispositivos constitucionais devem ser cumpridos e essa se revela a sua função mais sublime. Elas devem se tornar o esteio para a concretização dos direitos fundamentais. A sua atuação como legislador negativo somente deve ser verificado quando o Legislativo descumprir as cominações procedimentais que legitimam a produção jurídica. Como legislador positivo, o Poder Judiciário somente pode atuar para garantir a realização dos comandos normativos da Constituição e na extensão do programa normativo expresso.

A solução para a crise de legitimidade por que passa a jurisdição constitucional, ao cumprir suas extensas funções, condizentes com um Estado Social que ampara os direitos dos cidadãos, é segundo Habermas densificar a taxionomia democrática de suas decisões, por intermédio de uma concepção procedimental da Constituição, que tente buscar uma maior legitimidade das decisões da jurisdição constitucional por argumentos racionais construídos no espaço público.

${ }^{20}$ HABERMAS, Jürgen. Fatti e Norme. Contributi a uma Teoria Discorsiva Del Diritto e Della Democrazia. Trad. Leonardo Ceppa. Milano: Edizione Guerini e Associati, 1996. p. 518. 
O Poder Judiciário deve zelar pela integridade de aplicação da Constituição, verificando se os procedimentos necessários e os parâmetros ético-morais foram seguidos e se a decisão tomada se legitimou nas discussões travadas no espaço público.

Para Habermas, a racionalidade constitucional deve ser amparada por princípios ético-jurídicos, traduzida em argumentos que obtém legitimidade no espaço público, garantindo assim às decisões da jurisdição constitucional uma certa previsibilidade. Ensina o mencionado autor: “A racionalidade legitimante da Corte Constitucional (proveniente da Constituição) vem especificada na perspectiva da aplicação jurídica, não na perspectiva de um legislador que interpreta e desenvolve o sistema dos direitos perseguidos no sentido da "policy”. A Corte utiliza-se de uma estrutura racional já confeccionada pelo legislador e legitimada na sua elaboração e a aplica em um caso singular de maneira coerente e sintonizada com os princípios jurídicos vigentes. Mas desta racionalidade, a Corte não pode dispor de forma livre para interpretar e desenvolver, em sede jurídica, o sistema dos direitos (que estalaria uma espécie de legislação implícita)". ${ }^{21}$

Pode-se traçar algumas simetrias entre Habermas e Häberle no sentido de que ambos têm o escopo de democratizar de forma mais incisiva as decisões da jurisdição constitucional, sendo estas expostas ao debate público, principalmente no concernente à ampliação dos intérpretes da Lex Mater. A diferença está em que a base da teoria habermasiana reside na racionalidade dos procedimentos que antecedem a decisão judicial, assumindo o processo judicial um caráter procedimental.

O alicerce de fundamentação da jurisdição constitucional reside no consenso obtido pelos cidadãos, como participantes da produção de um discurso racional, possibilitado pelo agir comunicativo; enquanto que o ordenamento jurídico garante a plenitude da autonomia privada que é um pré-requisito para a livre participação na formação do discurso racional, sem que haja a submissão de uma dessas esferas à outra. A jurisdição constitucional tem a missão de assegurar que o ordenamento jurídico cumpra essa função: velar pela autonomia privada. O modelo habermasiano de legitimação constitucional tem como essência procedimentos que têm o objetivo de resguardar o desenvolvimento do regime democrático de forma que possibilite a participação mais ampla possível dos cidadãos.

Ele planteia a teoria de legitimação da jurisdição constitucional, através de um procedimento calcado no agir comunicativo. Critica as teorias substancialistas de legitimação porque elas teriam um traço autoritário, na medida em que impõem à realização de valores materiais contidos na Constituição, desestimulando a participação dos cidadãos nos espaços públicos porque alça a jurisdição constitucional como última referência. Habermas desaprova o que denomina de "colonização do mundo da vida”, processo provocado pela expansão da jurisdição constitucional que tolhe a autonomia privada dos cidadãos, diminuindo a sua margem de atuação.

O argumento mais importante utilizado por Habermas para explicar a sua rejeição às teses substancialistas é porque na aplicação dessa essência, contida no

${ }^{21}$ HABERMAS, Jürgen. Fatti e Norme. Contributi a uma Teoria Discorsiva Del Diritto e Della Democrazia. Trad. Leonardo Ceppa. Milano: Edizione Guerini e Associati, 1996. pp. 311-312. 
texto constitucional, é descurado o pluralismo sócio-político-econômico, existente nas sociedades atuais, onde há uma ampla fragmentação de classes sociais, que impede o estabelecimento de substâncias que contemplem os interesses de todos os segmentos sociais. Segundo Lenio Streck, Habermas propõe que o Tribunal Constitucional deva ficar limitado à tarefa de compreensão procedimental da Constituição, restringindo-se a preservar os procedimentos de criação democrática do Direito. ${ }^{22}$

A legitimação da jurisdição constitucional através, da teoria discursiva do direito, representa uma alternativa tanto à concepção liberal do Estado quanto à sua concepção comunitarista.

Para Habermas, os direitos subjetivos remetem a uma ordem jurídica objetiva, que obedece à lógica do processo comunicativo, assim, as normas jurídicas são formuladas por atores políticos que agem dentro de uma reflexão do nexo ético vital. Dessa reflexão, ele traça uma relação entre os direitos fundamentais e a autonomia dos cidadãos, já que a livre participação dos cidadãos no processo comunicativo permite a formulação de dispositivos jurídicos que assegurem a concretização dos direitos subjetivos.

A tensão entre os direitos fundamentais e o princípio da soberania popular, apresentada no pensamento de Sunstein ou de Frank Michelman para a legitimação da jurisdição constitucional, é para Habermas ultrapassada quando a legitimidade do ordenamento jurídico corresponde ao consenso dos cidadãos como participantes do processo comunicativo, criando uma conexão com o sistema de direito, que garante a autonomia privada e, ao mesmo tempo, com a supremacia dos mandamentos constitucionais.

Para a sua teoria o objetivo mais importante é a formação de procedimentos éticos de deliberação, que possibilitem a formação de consensos, ao invés da busca de valores éticos à priori.

\section{BIBLIOGRAFIA}

ADEODATO, João Maurício. Ética e Retórica. Para uma Teoria da Dogmática Jurídica. São Paulo: Saraiva, 2003.

ABBAGNANO, Nicola. Dicionário de Filosofia. Tradução: Alfredo Bosi. São Paulo: Martins Fontes, 2000.

BARALDI, Cláudio; CORSI, Giancarlo; ESPOSITO, Elena. Semântica e Comunicazione. L'evoluzione delle idee nella prospettiva sociológica di Niklas Luhmann. Bologna: Clueb, 1987.

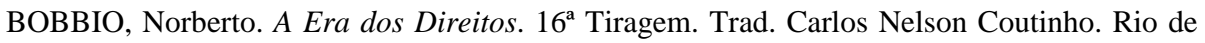
Janeiro: Editora Campus, 1992.

DWORKIN, Ronald. Uma Questão de Princípio. Trad. Luís Carlos Borges. São Paulo: Martins Fontes, 2000.

HABERMAS, Jurgen. Direito e Moral. Trad. Sandra Lippert. Lisboa: Instituto Piaget, 1992.

HABERMAS, Jürgen. Fatti e Norme. Contributi a uma Teoria Discorsiva Del Diritto e Della Democrazia. Trad. Leonardo Ceppa. Milano: Edizione Guerini e Associati, 1996.

${ }^{22}$ STRECK, Luiz Lenio. Jurisdição Constitucional e Hermenêutica. Uma Nova Crítica do Direito. Porto Alegre: Livraria dos Advogados, 2002. p. 138. 
HABERMAS, Jürgen. Direito e Democracia. Entre Facticidade e Validade. V. I. Trad. Flávio Beno Siebeneichler, Rio de Janeiro: Tempo Brasileiro, 1997.

KLEINBERG, Stanley S. The Necessity and Limitations of Rational Argument. Massachusetts: Blackwell, 1991.

MOREIRA, Luiz. Fundamentação do Direito em Habermas. 2. ed. Belo Horizonte: Mandamentos, 2002.

SALDANHA, Nelson. Da Teologia à Metodologia. Secularização e Crise no Pensamento Jurídico. Belo Horizonte: Del Rey, 1993.

SOUZA NETO, Cláudio Pereira. Jurisdição Constitucional, Democracia e Racionalidade Prática. Rio de Janeiro: Renovar, 2002.

STRECK, Luiz Lenio. Jurisdição Constitucional e Hermenêutica. Uma Nova Crítica do Direito. Porto Alegre: Livraria dos Advogados, 2002.

SUNSTEIN, Cass. R. Republic. Com. New Jersey: Princeton University, 2002.

WEBER, Max. Economia e Società. Sociologia Del Diritto. III. Trad: Giorgio Giordano. Milano: Edizione di Comunita, 1995. 